\title{
LAS ORDENANZAS LOCALES EN LA CORONA DE CASTILLA COMO FUENTE HISTORICA Y TEMA 19.DE INVESTIGACION (SIGLOS XIII AL XVIII)
}

\author{
352.077.6: 946
}

por

Miguel-Angel Ladero Quesada e Isabel Galán Parra Universidad de Madrid

SUMARIO: I. INTRODUCCION.-II. LAS ORDENANZAS EN LA HISTORIA DE LA LEGISLACION LOCAL.-III. TEXTOS DE ORDENANZAS.-IV. EL CONTENIDO DE LAS ORDENANZAS. V. CONCLUSION.

\section{INTRODUCCION}

La promulgación de normas jurídicas de aplicación local en núcleos urbanos castellanos y leoneses y en las áreas rurales dependientes de ellos atravesó por varias etapas desde los últimos decenios del siglo xr. En la primera, lo habitual era que la Corona dictara un Fuero y, a menudo, otorgara también diversos privilegios en el momento o período inicial de la repoblación y organización de la correspondiente localidad, y eso fue lo más corriente hasta mediados del siglo XIII, de modo que Fueros y privilegios han sido considerados como las primeras formas de Derecho local existentes en la 
historia castellano-leonesa (1), aunque hay mucho de artificial en la distinción entre Derecho local y Derecho territorial que antaño se hizo, si se tiene en cuenta tanto su respectivo contenido normativo como el que el ámbito de aplicación del Fuero era no sólo el núcleo principal, sino también el territorio y lugares - alfoz, tierra- que dependían de él (2). Una característica importante es que un mismo Fuero, o sus derivaciones más o menos matizadas, se aplicaban a la gobernación y administración de múltiples localidades, lo que ha permitido establecer relaciones y formar familias con este tipo de normas jurídicas, así como poner de relieve la falta de especificidad o peculiaridad de los mismos con relación a tal o cual núcleo donde estuvieron vigentes (3).

\section{LAS ORDENANZAS EN LA HISTORIA DE LA LEGISLACION LOCAL}

Desde el último tercio del siglo XIII, la insuficiencia o inadecuación de los Fueros se suplió mediante la promulgación de Ordenamientos y Ordenanzas relativos a las localidades concretas donde iban a tener aplicación. La extensa época de las Ordenanzas -que así las llamaremos para simplificar-cubre más de quinientos años, hasta el final del Antiguo Régimen, e incluso en épocas más cercanas han seguido siendo la expresión normativa más característica de los poderes municipales. Es preciso señalar, ante todo, que la potestad para emitirlas correspondía tanto a la Corona como a los Municipios, y en las áreas de jurisdicción señorial, a los diferentes señores. Eran potestades convergentes, y no contrapuestas, hacia un mismo objeto de reglamentación, pero conviene recordar que, en caso de concurrencia, prevalecía siempre la de la Corona o el señor sobre la del organismo municipal. Esto, sin embargo, no ocurría muchas veces. Primero, porque la Corona emitió pocos

(1) Jesús LALINDE ABAdía: Iniciación historica al Derecho español, Barcelona, 1978, pág. 125: diferencia entre Fueros, Privilegios y Ordenanzas municipales.

(2) Aquilino Iglesia FerReIRos: «Derecho municipal, Derecho señorial, Derecho regio», en Historia. Instituciones. Documentos, 4 (1977), 115-197. Sobre las formas de creación de derecho en la Edad Media y la superación de la dicotomía Derecho territorial/Derecho local.

(3) Alfonso García Gallo: «Aportación al estudio de los Fueros», en Anuario de Historia del Derecho Español (AHDE) (1956), 387-446. Rafael GIBERT: «El Derecho municipal de León y Castilla», en $A H D E$ (1961), 695-753. Un resumen y biblio grafía actualizados en José Manuel PÉrez-Prendes: Curso de Historia del Derecho español, Madrid, 1978, caps. diez y catorce. 
privilegios y Ordenamientos después del siglo xIv, época en la que todavía son más frecuentes que las Ordenanzas emitidas por los Municipios, aunque muchas cartas y provisiones reales se incorporaron a Ordenanzas posteriormente, y segundo, porque las normas municipales elaboradas por los Concejos desde entonces solían ser presentadas para su examen y refrendo ante el Consejo Real, bien directamente, bien a través del Corregidor que hubiera en la ciudad o villa interesada (4). Igualmente, en las zonas de señorío era frecuente que el titular del mismo hiciera suyas y promulgara de nuevo, si lo consideraba adecuado, Ordenanzas ya vigentes emitidas por los Municipios.

De modo que teniendo en cuenta esta jerarquización y multiplicidad de la potestad normativa, se comprende que las Ordenanzas hayan sido la manifestación más continua y prolongada de la autonomía de los poderes locales a lo largo de medio milenio. La influen. cia e interés de la Corona explica que el fenómeno de recopilación de Ordenanzas y la integración en ellas de normas generales emanadas de los órganos de poder monárquicos, haya madurado desde finales del siglo xv y en la primera mitad del xvi, época en la que, hay que recordarlo, se consuma también el movimiento recopilador de legislación general del Reino, desde las llamadas Ordenanzas Reales, de Montalvo, hasta la Nueva Recopilación, de Felipe II. Después del gran período compilador que acabamos de señalar, en las Ordenanzas locales más tardías, a menudo impresas, se pone de manifiesto claramente el peso de la autoridad regia, del Consejo Real o del Corregidor, y se acentúa la inclusión de normas de Derecho regio general, expresamente, o el sometimiento a ellas de la legislación local. Y en el ámbito de los señoríos, crece la función del señor jurisdiccional y mengua la de los Concejos en la emisión de tal normativa.

La historia de esta legislación sería un buen indicador, por tanto, de las relaciones y peso respectivo de los núcleos de poder constituidos en el llamado Estado moderno, por la Corona, por las Municipalidades del Reino y por los titulares de jurisdicción señorial. Se manifestaría cómo, a pesar del aumento del campo de acción e intervenciones de la primera, y de su indiscutida preeminencia -que nadie eludió ya en la Edad Media, aunque, a veces, sus órdenes se

(4) Benjamín González Alonso: El Corregidor castellano (1348-1808), Madrid, 1970. A. Bermúdez Aznar: El Corregidor en Castilla durante la Baja Edad Media (1348-1474), Murcia, 1974. 
obedecieran, pero no se cumplieran, según tradicional expresión-, hubo un campo de acción autónoma muy considerable de los Municipios en el ámbito administrativo (5). Y lo hubo más cuando eran de realengo, acaso como jurisdicción habitual delegada del Rey y vigilada por su Corregidor, que no en los de señorío, donde la mayor proximidad de los agentes del poder aristocrático y el interés más inmediato y cotidiano del señor en el gobierno y administración de sus estados, reducía mucho la posibilidad de autonomía municipal en todos los planos - normativo, gubernativo, hacendístico-, aunque nunca la destruyera por completo.

Así, pues, las Ordenanzas son el amplio período final de evolución de las formas de Derecho local, en unos siglos caracterizados, ya desde el xIII, por la territorialización cada vez más amplia de las normas legales, favorecida por los principios jurídicos de raíz romanista y por el auge de la autoridad monárquica, de modo que en la prelación de uso de Leyes eran las normas locales subsidiarias con respecto a las territoriales emanadas de la Corona. Así lo dispuso Alfonso XI ante las Cortes de Alcalá de 1348: ante todo, los Tribunales habrían de atenerse a la legislación regia (6). En el campo no cubierto por ella, a los Fueros municipales. Por último, como fuente de Derecho supletoria, al «Derecho común», representado en la Corona de Castilla por Las Partidas de Alfonso X. Pero, además, como ya se ha indicado, en la Baja Edad Media no hay Fueros nuevos: se dio este nombre, a veces, a los Ordenamientos en que los Reyes Católicos regularon el nombramiento de oficios concejiles en los Municipios recién constituidos del Reino de Granada y en Gran

(5) Alfonso García Gallo: "Crisis de los derechos locales y su vigencia en la Edad Moderna», en IV Jornadas franco-españolas de Derecho comparado, Barcelona, 1958, 69-81. Benjamín GonZÁlez Alonso: «Sociedad urbana y gobierno municipal en Castilla (1450-1600)», en Sobre el estado y la administración de la Corona de Castilla en el Antiguo Régimen, Madrid, 1981. En el mismo lugar: «Reflexiones históricas sobre el Estado y la autonomía regional en España». Del mismo autor: "Las Comunidades de Castilla y la formación del Estado absoluto", en Revista de Historia del Derecho (Granada), II-1 (1978), 265-313. Pedro FernANDEZ Albaladejo: «Monarquía y Reino en Castilla, 1538-1623», en XIV Settimana di Studio, Prato (abril 1982). Rafael GIBERT: "La ciudad castellana bajo los Reyes Católicos», en Archivo de Derecho Público, 5 (1952), 85-97. Miguel Angel Ladero Quesada: «El Poder central y las ciudades en España del siglo xJv al final del Antiguo Régimen», en Revista de Administración Pública (1981), 173-198. José Manuel de BERnARdo AREs: «Las Ordenanzas municipales y la formación del Estado moderno", en I Coloquio sobre la ciudad hispánica, La Rábida, septiembre de 1981 (basado en las de Córdoba).

(6) J. M. Pérez Prendes: Curso de Historia..., págs. 467-470. 
Canaria; pero a decir verdad, muy poco tenían en común con los Fueros de la época plenomedieval (7).

Los Ordenamientos y Ordenanzas del tiempo que ahora nos interesa cubrían campos jurídicos mucho más reducidos que los de tales antiguos Fueros, porque no se ocuparon, o apenas, de cuestiones tocantes a Derecho civil y penal o procedimiento procesal. En cambio, como en algunos de ellos, regulan los procedimientos y ámbitos de actuación de autoridades locales, la forma de nombrarlas o elegirlas, y la organización de muchos aspectos de la actividad económica agraria, artesanal o mercantil, así como lo tocante a fiscalidad municipal. Y, además, lo hacen con más detalles y especificidad que los antiguos Fueros, de los que a veces son prolongación o ampliación en estos aspectos, porque así como el Fuero podía referirse o afectar indiscriminadamente a muchas localidades, todas aquellas a las que se otorgó, las Ordenanzas se dirigen y aplican sólo a un lugar o grupo de lugares homogéneo, de modo que pueden tener un valor mayor para los historiadores que quieran estudiar situaciones específicas e incluso cotidianas de la vida en una localidad o territorio concretos.

Por ello, más todavía que las cuestiones histórico-jurídicas que hemos esbozado (8), o que el análisis de las relaciones de poder entre Municipios, Corona y señores, a través de las Ordenanzas locales, lo que puede interesar al historiador es el estudio de su contenido, que se refiere a los aspectos más variados de la vida y que permite establecer paralelismos y líneas evolutivas o situaciones de conjunto, pero también profundizar en el conocimiento de las Comunidades locales, de sus manifestaciones vitales y de sus formas de

(7) J. M. PÉrez Prendes: «El Derecho municipal del Reino de Granada (Consideraciones sobre su investigación)», en Revista de Historia del Derecho (Granada), II, 1 (1977-78), 371-459. J. MoReno CASADO: Fuero de Baza. Estudio y transcripción, Granada, 1968. Carlos Asenjo Sedano: El Fuero nuevo de la ciudad de Guadix, Guadix, 1974. Antonio Malpica Cuello: «El Fuero nuevo del Reino de Granada y el Fuero de Gran Canaria (Notas para el estudio de la Administración municipal)», en III Coloquio de Historia Canario-Americana (1978), Las Palmas, 1980, I, 319-342. Jesús Lalinde Abadía: «El Derecho castellano en Canarias», en Anuario de Estudios Atlán:ticos, 16 (1970), 18-35.

(8) Sobre el interés de juristas e historiadores del Derecho por las Ordenanzas, vid. las obras siguientes, útiles conceptualmente: Adolfo PosaDA: Evolución legislativa del Régimen local en España (1812-1906), Madrid, 1910, y «Ordenanzas municipales», en Enciclopedia Juridica Española Seix, XXIV. Eduardo GARcía dE ENTERRf́A: «Dictamen sobre la legalidad de las Ordenanzas municipales», en Revista de Administración Pública, 50 (1966), 311 y sigs. Antonio EMBID IRUJo: Ordenanzas y Reglamentos municipales en el Derecho español, Madrid, 1978. Esteban Corral García: Ordenanzas de los Concejos castellanos. Formación, contenido y manifestaciones (siglos XIII-XVIII), Madrid, Instituto de Estudios de Administración Local, 1981 (ejemplar mecanografiado, estudio muy valioso). 
organización durante varios siglos, analizando, es cierto, más las estructuras y los fenómenos de «larga duración» que no las coyunturas, acontecimientos concretos e incluso tendencias, que tienen una cabida mucho menor, muy escasa, en este tipo de fuente documental.

Es posible hacerlo porque han llegado a nuestra época cientos: de Ordenanzas emitidas entre los siglos XIII y XVIII, impresas unas veces en su época o en otra posterior, inéditas en su mayoría y conservadas en los Archivos municipales, señoriales o, a veces, ein los del Consejo Real o Consejo de Castilla, tanto en el Archivo General de Simancas como en el Histórico Nacional de Madrid. Sería de gran interés formar y poner a disposición de los investigadores un inventario general de Ordenanzas y un fondo microfilmado de todas ellas, pero la tarea de formación de este corpus es difícil y se presenta como objetivo a plazo medio (9). Mientras tanto, hay la posibilidad de estudiar las Ordenanzas ya editadas o de llegar a conocer las de algún ámbito regional explorado sistemáticamente a este respecto.

\section{TEXTOS DE ORDENANZAS}

El objeto de estas páginas introductorias es precisamente acopiar noticias sobre las Ordenanzas conocidas, especialmente de los siglos XV y XVI, y esbozar un programa de estudio comparando sus respectivos contenidos. Por eso, se expone a continuación las noticias que hay sobre diversas Ordenanzas castellanas. En algunas ocasiones su contenido ha sido utilizado en diversos libros de historia local, e incluso se han puesto a contribución en algunas investigaciones de historia económica (10), donde se ponen de relieve

(9) Sobre los intentos de colección en este siglo, vid. Juan de La Cierva: Notas de mi vida, Madrid, 1955, pág. 111: se refiere a la colección de Ordenanzas que mandó formar en 1912.

(10) Por ejemplo, aunque muy desiguales entre sí, las obras siguientes: Eduardo IBARRA: «El problema de las subsistencias en España al comenzar la Edad Moderna. La carne», en Nuestro Tiempo, 1926; El problema cerealista en España durante el reinado de los Reyes Catolicos, Madrid, 1942, y Documentos de asunto económico ca rrespondientes al reinado de los Reyes Católicos (1475-1516), Madrid, 1917. Paulino IRADIEL MURUGARREN: Evolución de la industria textil castellana en los siglos XIIIXVI. Factores de desarrollo, organización y costes de la producción manufacturera en Cuenca, Salamanca, 1974. Miguel Angel LADERo QUESADA: «Ordenanzas municipales y regulación de la actividad económica en Andalucía y Canarias. Siglos xIV-xvir, en II Coloquio de Historia Canario-Americana, Gran Canaria, 1979, 143-156, y «La caza en la legislación municipal castellana. Siglos xıII a Xviı», En la España Medieval. 
los elementos de relación y comparación entre Ordenanzas de diverso origen. Pero, en general, falta la búsqueda y relación previas, lo más completas posibles, de estos documentos, para construir investigaciones comparativas a partir de ellos, teniendo siempre en cuenta la época o contemporaneidad de su promulgación y, a la vez, la permanencia de las estructuras administrativas y de vida social y económica tradicionales que reflejan.

Por otra parte, no hay que olvidar que la normativa municipal no siempre alcanzaba la categoría de Ordenanza. Podía contenerse en actas de acuerdos tomados en sesiones de Cabildo, en documentos emanados de oficiales concejiles -mayordomos, fieles, almotacenes, alguaciles...- o en cuadernos de condiciones de arrendamiento de rentas locales. De modo que en estudios concretos sobre un lugar, hay que combinar el contenido de las Ordenanzas con el de estos otros tipos documentales, cuando se conservan (11).

Para el área de Galicia se cuenta con las ediciones de LÓPEZ FERreiro, en que se mezclan Fueros locales y Ordenanzas de Santiago y su tierra (12); de MARTf́NEZ SuEIRo, cuyo texto incluye Ordenanzas municipales de Orense de 1423 a 1509 (13), y con la edición de las Ordenanzas de Vigo de 1560 (14). Asturias cuenta con más ediciones, relativamente, en los antiguos libros de VigIL y SANGRADOR: el primero incluye las Ordenanzas de Oviedo de 1245 y 1274 , entre las más antiguas conocidas (15), y el segundo, una am-

Madrid, 1981, 193-221. A. Bernal, A. Collantes de Terán, A. Garcf́a Baquero: «Sevilla: de los gremios a la industrialización», en Estudios de Historia Social (Madrid), 5-6 (1978), 7-307.

(11) Ejemplos de libros de acuerdos editados o estudiados y de la forma de proceder en Cabildo, en: Raimundo Rodríguez: «Libro del consistorio de la Muy Noble y Muy Leal ciudad de León», en Archivos Leoneses (1953), 5-77, 111-112, IX (1955), 123-181. Juan A. Bonachia Hernando: El Concejo de Burgos en la Baja Edad Media (1345-1426), Valladolid, 1978; Libros de Acuerdos del Concejo Madrileño, I a III (1464-1497), Madrid, 1932-1979; Acuerdos del Cabildo de Tenerife (1497-1525), ed. y estudio por Elías SERRA RÁfols y Leopoldo de la RosA, 1948-1970, 4 vols. Roberto Roldán Verdejo y Candelaria Delgado González: Acuerdos del Cabildo de Fuerteventura (1605-1728), La Laguna de Tenerife, 1967-1970, 2 vols. Documentación hacendística originada en Cabildo, por ejemplo, en el catálogo de Francisco CollaNTES DE TERÁN: Inventario de los papeles de mayordomazgo, Sevilla, 1968-1980, 3 vols.

(12) A: López FERreiro: Fueros municipales de Santiago y su tierra, Santiago, 1895-1896, 2 vols.

(13) Manuel Martínez Sueiro: Fueros de Orense, Orense, 1912 (repr. 1978).

(14) Ordenanzas de la villa de Vigo del año 1560, Vigo, 1965. Transcritas por José GonzÁlez Posada-CurRos.

(15) C. M. VIGIL: Colección histórico-diplomática del Ayuntamiento de Oviedo, Oviedo, 1889. 
plia colección de Fueros, Cartas-pueblas y Ordenanzas (16). Muy poco, por el contrario, en la zona cántabra, si se exceptúa el estudio. de Fueros locales, más que Ordenanzas, hecho por MaRTínez DíEz (17) y la edición de las de Cabezón de la Sal (18). Las Ordenanzas vizcaínas conservadas o conocidas no son, en general, anteriores: al xv, si se exceptúa la de la Cofradía de Pescadores de Bermeo, año 1353, que publicara LABAYRU (19), y las de la villa de Bilbao. correspondientes a los siglos XV y XVI -compilaciones de 1526, 1548 y 1593 - (20), anteriores a las ediciones de 1682 y 1711 , que es: la misma colección, mandada imprimir por el Municipio (21). MoNREAL CIA estudia también Ordenanzas de Portugalete, Durango, Lequeitio, Marquina y Bermeo (22). También en el siglo xvirI se imprimieron las Ordenanzas de gobierno de San Sebastián, en 1760 (23), y de Vitoria, en 1747, y, de nuevo, en 1761 (24). Hay noticia de las de Salinas de Añana, conservadas en su Archivo municipal (25).

Los Ordenamientos otorgados a Burgos por Alfonso $\mathrm{X}$ recogen, en parte, disposiciones generales de Cortes (26). Para los siglos bajomedievales hay Ordenanzas conservadas en el Archivo municipal

(16) M. SANGRAdor Vitores: Historia de la Administración de Justicia y del antiguo Gobierno del Principado de Asturias y colección de sus Fueros, Cartaspueblas y antiguas Ordenanzas, Oviedo, 1866.

(17) Gonzalo Martínez Díez: «Fueros locales en el territorio de la Provincia de Santander», en $A H D E$ (1976), 527-608.

(18) Rogelio PÉREz Bustamante: Ordenanzas antiguas de la villa de Cabezón. de la Sal, Cabezón de la Sal, 1980.

(19) Estanislao J. Labayru y Goicoechea: Historia General del Señorío de Bizcaya, Bilbao, 1895-1903, vol. II, 820-839.

(20) A. MAÑARICUA: "Las Ordenanzas de Bilbao impresas en 1669», en Estudios: de Deusto, IV (1956), 475-480. Hay compilaciones de las Ordenanzas de 1526, 1548 y 1593, más ediciones posteriores de 1682 y 1711. Las de 1593, editadas por A. MAÑARICUA: Las Ordenanzas de Bilbao de 1593. Estudio preliminar y texto, Bilbao, 1954.

(21) Ordenanzas de la noble villa de Bilbao, 1682, 1711.

(22) Gregorio Monreal Cía: Las instituciones públicas del Señorio de Vizcaya. hasta el siglo XVIII, Bilbao, 1974. Reseña de todas las Ordenanzas municipales.

(23) Ordenanzas de gobierno, méthodo de distribuir propios y arbitrios de San Sebastián y Reglamento Real de Derechos que debe exigir en los géneros de mar y tierra, Pamplona, 1760.

(24) Ordenanzas de la Muy Noble y Muy Leal ciudad de Vitoria, 1747. Quaderno de las Leyes y Ordenanzas con que se govierna esta muy noble y muy leal Provincia de Alava, Vitoria, 1761.

(25) Agustín Millares CaRlo: Notas bibliograficas acerca de Archivos municipales..., Madrid, 1952, 19-20.

(26) Ismael GaRcía RAMILA: «Ordenamientos de posturas y otros capítulos generales otorgados a la ciudad de Burgos por el Rey Alfonso X», en Hispania, V (1945), 179-235, 385-439, 605-650. 
de la ciudad, y también en el de Simancas (27), y, por fin, las de época moderna se compilaron y publicaron en 1615 , y de nuevo, en 1747 (28). En la zona burgalesa, cabe recordar las ediciones de las Ordenanzas de Toba de Valdivieso (29), Medina de Pomar de 1481 y 1495 (30) y Oña (31). Para el sector riojano, se cuenta ya con las de Logroño, hechas en 1676 (32), y de nuevo en 1807 (33), y aprobadas en ambas ocasiones por el Consejo de Castilla. Otras menores se refieren a Laguna de Cameros (34); Ojacastro, del siglo XvI (35); Bujedo, aldea de Miranda de Ebro, del xviı (36), y Ezcaray (37), editadas todas ellas recientemente.

La situación de las ediciones sobre León es muy semejante: hay Ordenanzas inéditas de fines del siglo Xv y del xvi conservadas

(27) Ordenanzas dadas a la ciudad de Burgos en 15 de febrero de 1497, por los Reyes Católicos, para completar y aclarar sus antiguos Estatutos y Ordenanzas (A. M. Burgos, Sección Histórica, núm. 1.443 bis). Ordenanzas de la alhóndiga del pan de Burgos (Simancas, Registro General del Sello, septiembre 1513). Ordenanzas de la ciudad de Burgos, año 1516, en Simancas, Consejo Real, leg. 593, núm. 19. J. A. Bonachia Hernando: El Concejo... G. Díez de la lastra: "Las primeras Ordenanzas de los zapateros burgaleses», en $A H D E$ (1929), 441 y sigs. Luciano SERrano: Los Reyes Católicos y la ciudad de Burgos, Madrid, 1943, pág. 212. Julián SAINZ DE BARANDA: La ciudad de Burgos y su Concejo en la Edad Media, Burgos, 1967, 2 vols.

(28) Ordenanzas de la muy noble y muy más leal ciudad de Burgos, Burgos, 1615. Ordenanzas de la muy noble y muy más leal ciudad de Burgos, cabeza de Castilla y cámara de Su Majestad, aprobadas por Su Majestad y señores de su Real y Supremo Consejo de Castilla en tres de febrero de mil setecientos cuarenta y siete, 1747, Madrid.

(29) Floriano Ballesteros Caballero: «Ordenanzas del Concejo e inventario de documentos de Toba de Valdivieso (Burgos)», en Boletín de la Institución Fernán González, 183 (1974), 323-354.

(30) Julián GaRcía SAINZ dE BaRANDa: Apuntes históricos sobre la ciudad de Medina de Pomar, Burgos, 1917.

(31) María del Carmen Pescador del Hoyo: "Ordenanzas laborales de la villa de Oña a fines del siglo XV», en Cuadernos de Historia de España, XXI-XXII (1954), 345-357.

(32) Ordenanzas hechas por la muy noble y muy leal ciudad de Logroño, con que se rige y govierna la policía de ella. Confirmadas por Su Magestad el año de 1676. Nuevamente editadas en 1744.

(33) Ordenanzas para el gobierno del campo de la muy noble y muy leal ciudad de Logroño. Aprobadas por el Consejo de Castilla en 7 de septiembre de 1807.

(34) María Isabel Falcón PÉrez: «Ordenanzas municipales de Laguna de Cameros», en Suma de estudios en homenaje al Ilmo. Dr. Angel Canellas López, Zaragoza, 1969, 279-303.

(35) José J. Bautista Merino Urrutia: Ordenanzas de Ojacastro (Rioja) (siglo XVI), Madrid, 1958.

(36) María del Carmen Pescador del Hoyo: «Ordenanzas municipales de Bujedo a fines del siglo XVII», en Revista de Archivos, Bibliotecas y Museos, 1976, 697-731.

(37) Pedro Longas Bartibas: «Ordenanzas municipales de Ezcaray», en $A H D E$ (1961), 465-472. 
en su Archivo municipal y en el de Simancas (38), pero las primeras impresas son las confirmadas por Carlos V, y se reeditaron en 1669 (39). Interesan también el Resumen de las politicas ceremonias..., compuesto por CABEZA DE VACA en 1693 (40), y los textos de Ordenanzas rurales publicados, relativos a la Tierra de Ordás (41), a la montaña de León (42) y a otros Concejos de aquel territorio (43). Las Ordenanzas de Valladolid se imprimieron en el siglo xvi y tuvieron hasta tres reediciones sin modificación, de las que conocemos las de 1605 y 1763, aunque recientes investigaciones demuestran que la villa también las tuvo en la Edad Media (44). También ocurrió lo propio en Medina del Campo, que las compiló a fines del siglo xv, y en Zamora, ambas en curso de edición (45). En 1590 promulgaba las suyas Villa de San Miguel, cerca de Zamora (46). En la misma línea del Duero, la villa señorial de Peñafiel había recibido ya las primeras Ordenanzas de su señor, el famoso Don Juan Manuel, a comienzos del siglo xIV (47).

En la Extremadura segoviana y en sus áreas próximas hay muchos ejemplares de Ordenanzas, pero también grandes vacíos y una notable dispersión en el tiempo. De la misma Segovia y su tierra se sabe más bien poco, aunque las Ordenanzas concejiles de la ciudad, de fines de la Edad Media, han comenzado ya a manejar-

(38) Simancas, Consejo Real, 83-81: Ordenanzas de León, sobre trịo y harina, de 29 de enero de 1511. Vid. las reseñadas por José A. Martín Fuertes y César Alvarez Alvarez: Archivo histórico municipal de León. Catálogo de documentos, León, 1982.

(39) Ordenanzas para el govierno desta muy noble y muy más leal ciudad de León, su tierra y jurisdicción, hechas por los señores justicia y regimiento della. Confirmadas por la magestad del señor emperador Carlos Quinto, León, 1669.

(40) Francisco CABEZA DE VACA: Resumen de las politicas ceremonias con que se gobierna la noble, leal y antigua ciudad de León, cabeza de su reyno, Valladolid, 1693 (reimpresión, León, 1978).

(41) Florentino Agustín Díez González: La noble tierra de Ordás (Monografía histórica y concejil), Madrid, 1950.

(42) Francisco FlóREZ de QuiÑones y DíaZ: "Costumbres jurídicas de la montaña de León», en Gaceta del Notariado (Madrid), 1895.

(43) Elías LóPEZ MORÁN: "Derecho consuetudinario leonés», en Revista General de Legislación y Jurisprudencia, XC (1897), págs. 737 y sigs.

(44) Es la tesis doctoral, en curso, de Adeline Rucouor. Las ediciones de Valladolid, 1605 y 1763, llevan el mismo título: Ordenanzas con que se rige y govierna la República de la muy noble y muy leal villa de Valladolid.

(45) Las de Medina del Campo, en curso de estudio por Carlos Alvarez (Archivo Provincial de Soria), y las de Zamora, por Salustiano Moreta Velayos (Colegio Universitario de Zamora). Ambas se conservan en los respectivos Archivos municipales.

(46) María del Carmen Pescador DEL Hoyo: "Cómo surge una villa en el siglo xvi. San Miguel de la Ribera y sus Ordenanzas municipales», en RevisTA DE EsTUDJOS DE LA VIDA LOCAL, 148 (1966), 513-539.

(47) Andrés Jiménez Soler: Don Juan Manuel, Zaragoza, 1932, pág. 655: Ordenanzas dadas a la villa de Peñafiel. 
se (48), y hay unas de 1514 , confirmadas por Juana $I$, sobre viñas y heredades, montes y dehesas, que se conocen de antiguo (49), más otras de época moderna (50). También son de interés las Ordenanzas suntuarias de Valverde, lugar de la Comunidad segoviana (51), y las. de Carbonero el Mayor (52) o las de Villacastín. Las más antiguas, relativas a Riaza, fueron incluidas en su Colección Diplomática (53), y las hay también relativas a algunas aldeas de Sepúlveda (54). Cuéllar, por su parte, las compiló en 1545, con la aprobación de su señor el Marqués, y se imprimieron en 1547 (55), pero ya tenía Ordenanzas parciales dispersas, por ejemplo, las relativas a pinares del año 1492 (56). Todas ellas han sido objeto de un amplio estudio histórico-jurídico reciente (57). En 1583, el Rey aprobaba las Ordenanzas redactadas por el Concejo de Coca para su villa y tierra (58). En el sector soriano, por último, hay noticia de las de Agreda (59) y Yanguas (60).

Las Ordenanzas de Avila de 1485, a partir de una copia de 1771,

(48) En la tesis doctoral de María Asenjo GonzÁlez (Universidad de Madrid).

(49) Vid. Eugenio Larruga Y Boneta: Memorias..., X, pág. 272 (Ordenanzas. de Segovia y su Tierra en 1514). L. Redonet: «Ordenanzas para la Comunidad y Tierra de Segovia en 1514», en Boletín de la Real Academia de la Historia, C (1932), 279-283. Román RiazA: "Ordenanzas de ciudad y tierra», en $A H D E$ (1935), $468-495$.

(50) Vid. Manuel González Herrero: Segovia, pueblo, ciudad y tierra, Segovia, 1971. Luis García ARIAS: Segovia y el Derecho, Segovia, 1970. Salvador Bernal Martín: Usos y Fueros de Segovia, Segovia, 1974. Angel García Sanz: Desarrollo y crisis del Antiguo Régimen en Castilla la Vieja. Economía y sociedad en tierra de Segovia (1500-1814), Madrid, 1977.

(51) Julián de San Pelayo: Ordenanzas de Valverde, Comunidad y Tierra de Segovia, sobre la plata y paños de las bodas y otras cosas, Madrid, 1894.

(52) Antonio Martín LÁzaro: «Cuaderno de Ordenanzas de Carbonero el Mayor", en $A H D E$ (1932), $322-334$ (año 1409).

(53) Colección Diplomática de Riaza, ed. Antonio Ubieto ARteta, Segovia, 1959.

(54) Emilio SÁEz: «Ordenanzas de Santa María del Olmo, Zarzosa, Corral de Yuso y Villarejo de la Serna (1516)», en $A H D E$ (1951-1952), 1142-1151 (son aldeas de Sepúlveda, año 1516).

(55) Ordenanza de esta villa de Cuéllar (aprobadas por el Marqués en 20 de febrero de 1545), Valladolid, 1547.

(56) M. V.: "Ordenanzas de los pinares de la villa de Cuéllar», en Estudios Segovianos, XIX, 56-57 (1967), 325-336.

(57) Esteban CORRAL Garcfa: Las Comunidades castellanas y la villa y tierra antigua de Cuéllar, Salamanca, 1978.

(58) Ejecutoria y Ordenanzas de la villa y tierra de Coca (otorgadas por el Rey, tras su presentación por el Concejo, Madrid, 14 de mayo de 1583).

(59) A. Millares CaRlo: Notas bibliograficas acerca de Archivos municipales, págs. 55-56.

(60) En María Consuelo Delgado Martínez: Apuntes sobre la vida rural de la villa y tierra de Yanguas (Soria), siglos XII-XVI, Soria, 1981, págs. 154-164. Corresponden a comienzos del siglo xvi. 
fueron editadas hace años y han sido utilizadas frecuentemente (61). En algunos aspectos, las complementan los documentos relativos al "Asocio de la Universidad y Tierra de Avila», donde se incluyen Ordenanzas de 1384, relativas a usos agrarios (62). Contamos también con ediciones de las de Villatoro (63), y de las señoriales dadas al ducado de Alba en 1509, que eran de aplicación, por ejemplo, en El Barco de Avila (64) y seguramente en Piedrahíta (65). Para comarcas próximas hay buenos ejemplos editados, relativos a Miranda del Castañar (66), La Alberca (67), y uno inédito muy importante, las Ordenanzas de Béjar, recopiladas por el Concejo y refrendadas por su Duque en 1577 (68). Para Salamanca, otra de las urbes principales al sur del Duero, sólo se dispone, por el momento, de las Ordenanzas recopiladas y editadas en 1619 (69), pero el historiador local VILLAR y Macias da noticia y utiliza bastantes anteriores, del siglo XvI (70).

En las diversas urbes de Castilla la Nueva que se poblaron según Fueros o costumbres de las Extremaduras hubo también numerosas Ordenanzas bajomedievales, así como la común tendencia a compilarlas a finales del siglo xv o en el xvI. Así sucedió con las de Buitrago y su tierra (71). En Guadalajara, se cuenta con la

(61) Las Ordenanzas de Avila (manuscrito de 1485 y su copia de 1771), publicadas por el MARQuÉs DE Foronda..., con la cooperación del señor don Jesús MoliNERo, Madrid, 1917. Vid. también Ricardo BLASCO: «El problema del Fuero de Avila», en Revista de Archivos, Bibliotecas y Museos, IX (1954), 7-32.

(62) Asocio de la extinguida Universidad y Tierra de Avila, Avila, s. a. (aproximadamente 1920) (introducción histórica por Jesús Molinero FERNÁNDEZ).

(63) R. BLASco: "Ordenanzas municipales de Villatoro (Avila)», en AHDE (1935), 391-431.

(64) Nicolás de la Fuente Arrimadas: Fisiografía e Historia del Barco de Avila, Avila, 1925-1926, 2 vols. (I, págs. 290 y sigs.: Ordenanzas del Ducado de Alba, 1509).

(65) A. Millares Carlo: Notas bibliográficas..., pág. 20. En curso de estudio en la tesis doctoral de Elisa de Santos Canalejo (Universidad de Madrid).

(66) Santiago Stuart y Falcó (Duque de Berwick y de Alba): Noticias historicas de los Estados de Montijo y Teba, Madrid, 1915 (referencia a las Ordenanzas de Miranda del Castañar). Julián Alvarez Villar: La villa condal de Miranda del Castañar, Salamanca, 1975.

(67) Gabrielle Berrogain: «Ordenanzas de La Alberca y sus términos, Las Hurdes y Las Batuecas", en $A H D E$ (1930), 381-441. Vid. también, para un área muy cercana, José Luis MARTf́N: "Organización municipal de la villa de Gata en el siglo XVI», en Villes de l'Europe Méditerranéenne et de l'Europe Occidentale du Moyen Age au XIXe siecle, París, 1970, págs. 101-124.

(68) Ordenanzas de Béjar, recopiladas por el Concejo y editadas por el Duque de Béjar, a 10 de octubre de 1577. Ejemplares en el Archivo Municipal de Béjar y en el Archivo Histórico Nacional, Osuna, leg. 269.

(69) Ordenanzas de esta ciudad de Salamanca que, por su mandado, recopilo don Antonio Vergas de Carvajal, Salamanca, 1619.

(70) M. Villar y Macías: Historia de Salamanca, Salamanca, 1973 (reimpresión).

(71) Matías FERNÁNDEZ GaRcía: Fuentes para la historia de Buitrago y su tierra. Madrid, 1966, 2 vols. 
edición de las medievales, obra de Layna SerRano (72), y con un estudio inédito sobre las «Ordenanzas nuevas» de 1567 (73). Por el contrario, las Ordenanzas medievales de Madrid no han sido estudiadas sistemáticamente todavía, aunque sí utilizadas (74) y publicadas algunas hace tiempo (75). Las primeras modernas, correspondientes a 1585, lo fueron por GonZÁlez DE AmEZUA (76), y en su tiempo se imprimieron las relativas a urbanismo y construcción por Juan DE TORIJA, en 1661 (77). Algo semejante sucede en Cuenca, cuyo Archivo municipal conserva muchas, utilizadas en parte durante los últimos años (78).

Los Privilegios y Ordenanzas Reales de Toledo fueron editados ya en 1551 (79) y 1603 (80). Respecto a las Ordenanzas recopiladas por el Concejo en 1562 y aprobadas por el Consejo Real en 1590, fueron publicadas y estudiadas por A. MARTIN GAMERo en 1858, autor que da noticia de las anteriores, correspondientes, en general, al siglo Xv (81), y hoy en curso de transcripción (82). Algunas ediciones se refieren también a Ordenamientos reales y Ordenanzas concejiles del Xv, que, en parte, afectan a nuestro tema (83). Y, por fin,

(72) F. Layna Serrano: Historia de Guadalajara y sus Mendoza, Madrid, 1942 (apéndice documental del volumen primero).

(73) Salvador CAÑAs GómEZ: Las Ordenanzas «nuevas» de Guadalajara del 1567, Madrid, Instituto de Estudios de Administración Local (copia mecanografiada, sin fecha).

(74) Galo SÁnchez: El Fuero de Madrid y los Derechos locales castellanos, Madrid, 1932. Rafael GiberT y SÁNChEZ DE LA VEGA: El Concejo de Madrid. I: su organización en los siglos XII a XV, Madrid, 1949.

(75) Documentos del Archivo general de la villa de Madrid, Madrid, 1888-1909, 4 vols., ed. por Timoteo Domingo Palacio (Ordenanzas de los años 1500 a 1504 en los vols. III y IV). Documentos de la villa de Madrid, Madrid, 1932, ed. Angel PÉrez Chozas (Ordenanzas de 1380). Libros de Acuerdos del Concejo madrileño, Madrid, 1932-1979, 3 vols. (1464-1497).

(76) Agustín González DE AmezuA Y MAYo: Las primeras Ordenanzas municipales de la villa y corte de Madrid (1585), Madrid, 1926.

(77) Tratado breve, sobre las Ordenanzas de la villa de Madrid y policía de ella, por Juan de TORIJA, maestro arquitecto y alarife de ella, y aparejador de las obras reales, Madrid, 1661.

(78) Paulino Iradiel Murugarren: Evolución de la industria textil castellana (siglos XIII-XVI), Salamanca, 1974. María Dolores CABAXAS GonzÁleZ, en su tesis doctoral sobre Cuenca en la Baja Edad Media (Universidad de Madrid).

(79) Ordenanzas... de la imperial ciudad de Toledo, Toledo, 1551. 1603.

(80) Ordenanzas y privilegios de la ciudad de Toledo, Toledo, Pedro Rodríguez,

(81) Ordenanzas para el régimen y gobierno de la muy noble, muy leal $e$ imperial ciudad de Toledo, ed. por Antonio MarTín Gamero, Toledo, 1858. Son las recopiladas por el Concejo en 1562, aprobadas por el Consejo Real en 1590.

(82) Copias conservadas en el Archivo municipal de Toledo. Prepara su edición el Prof. Emilio SÁEz.

(83) Emilio SÁEZ SÁNchez: «Aranceles de Toledo», en AHDE (1942-1943), 546560. "Ordenamiento dado a Toledo por el Infante Don Fernando de Antequera, tutor de Juan II, en 1411», en $A H D E$ (1944), 499-556. «El libro del juramento del Ayunta- 
las de Talavera de la Reina han sido estudiadas recientemente (84). Otras muchas Ordenanzas correspondientes a villas y lugares menores, como Santorcaz (85) o Ajofrín (86), se han utilizado en ocasiones, pero hay muchas más inéditas y sin estudiar (87). Y también cabe recordar las de Alcalá de Henares, otorgadas por Felipe II en 1592 (88), o las muy tardías tocantes a los bosques y Reales Sitios de El Pardo, Aranjuez, El Escorial, Balsaín y otros, bastante diferentes, por su contenido y objetivos, de las municipales que ahora nos ocupan (89).

En las amplias tierras manchegas y extremeñas dominadas por las Ordenes Militares, apenas hay noticia de Ordenanzas locales, aunque la administración de los señoríos indudablemente las exigiría. Sí existen, en cambio, las tocantes a grandes Municipios de realengo y a algunos de señorío laico extremeños: Plasencia (90), Cáceres (91) y Trujillo (92) conservan compilaciones con Ordenanzas

miento de Toledo», en $A H D E$ (1945), 530-624. "Ordenanzas de los gremios de Toledo», en Revista del Trabajo, octubre de 1944 a agosto de 1945. Antonio Palomeque TORRES: «El fiel del juzgado de los propios y montes de la ciudad de Toledo», en Cuadernos de Historia de España, LV-LVI (1972), 322-399. F. JIMÉnez DE Gregorio: "Las Ordenanzas de Navalpino, lugar de los Montes de Toledo, en el siglo XVI», en Homenaje... Vicens Vives, Barcelona, 1965, II, 247-265.

(84) María Jesús SuÁrez Alvarez: Talavera de la Reina en la Baja Edad Media, Oviedo, 1978 (inédita). Mención en A. Millares TORRES: Notas bibliográficas..., página 59.

(85) Luis SÁNCHEz BELDA: «Fuero y Ordenanzas municipales de la villa de Santorcaz», en $A H D E$ (1945), 655-669.

(86) Conservadas en el Archivo de la Catedral de Toledo, año 1476.

(87) Sólo en el Archivo Histórico Nacional, Sección Osuna, hay Ordenanzas de los siglos XIV al XVII de diversos lugares, como Hita, Puebla de Alcocer, Ayora, Méntrida, Villa del Prado, San Martín de Valdeiglesias, Guadarrama, Manzanares el Real, Colmenar Viejo y Fuenlabrada. Y en Simancas, de Robledo de Chavela, año 1516 (Consejo Real, leg. 593, núm. 6), y otras en Registro del Sello, Memoriales de Cámara de Castilla y el mismo Consejo Real. La Puebla de Guadalupe conserva las suyas, del siglo xv, en el Archivo del Monasterio (códices núms. 77 y 78).

(88) Ordenanzas de la villa de Alcala de Henares, otorgadas en 1592 por Felipe II, Alcalá, 1685.

(89) Recopilación de las Reales Ordenanzas y Cédulas de los bosques reales del Pardo, Aranjuez, Escorial, Valsain y otros, Madrid, 1687 (compiladas por Pedro y Manuel Antonio de CervanTes). Ordenanzas para el gobierno del Real Sitio de Aranjuez, Madrid, 1795.

(90) Utilizadas por Elisa de Santos Canalejo: El siglo XV en Plasencia y su tierra. Proyección de un pasado y reflejo de una época, Cáceres, 1981.

(91) Utilizadas en su tesis doctoral por Fermina SANTANA ConsuEgRA: La villa de Cáceres en el siglo XV, Madrid, 1981 (Universidad de Madrid). Menciones en Pedro Lumbreras Valiente: Los Fueros municipales de Cáceres. Su Derecho público, Cáceres, 1974. Vid. también Pedro UlloA Y Golfín: Fueros y privilegios de Cáceres, 1676.

(92) María de los Angeles SÁnchez RUBIO: «Estructura socio-económica de la ciudad de Trujillo a través de sus Ordenanzas municipales (siglo Xv)», La Rábida, 1981 (Coloquio sobre la ciudad hispánica durante los siglos XIII a XVI). Estudiadas en su tesis doctoral por María del Carmen Fernández-Daza Alvear (Universidad de Madrid). 
de los siglos XIV y Xv. Para Cáceres se cuenta, además, con una recopilación posterior, hecha en 1569 (93). Las de Badajoz no se imprimieron por vez primera hasta 1767 , previa aprobación del Consejo Real (94). En su área hay noticias de las señoriales de Burguillos del Cerro, a mediados del xvi, y Capilla (95), y de las de Villalba (96); pero, sobre todo, de las compiladas por dos importantes poblaciones integradas en el señorío de la Orden de Santiago: las de Mérida, «reformadas de las antiguas», se editaron en 1677 (97), y las de Jerez de los Caballeros en 1758 (98).

Alcaraz era el enclave urbano más meridional de Castilla la Nueva dotado del Derecho de las Extremaduras: no parece que su Archivo municipal conserve Ordenanzas medievales, ni tampoco el de Ciudad Real (99). Más allá, el Reino de Murcia se había organizado con criterios algo diferentes, y hay alguna constancia de sus Ordenanzas ciudadanas bajomedievales, sobre todo para Murcia capital (100), aunque las ediciones, tanto en Murcia como en Lorca, son de Ordenanzas modernas (101). Se conocen también unas medievales de Calasparra, y otras de Caravaca; se han editado algunos Ordenamientos regios de los siglos XIII y XIV, y otros han sido manejados en monografías relativas a los siglos XIII al XVI (102).

(93) Ordenanzas del Ayuntamiento de Cáceres recopiladas en 1569, introducción por Antonio RuBio Rojas, Cáceres, 1974.

(94) Ordenanzas de la muy noble y muy leal ciudad de Badajoz..., aprobadas por el Supremo Consejo de Castilla en 28 de enero de 1767, Madrid, 1767.

(95) Las de Burguillos, en Carmen FERnández-DAZA: El señorio de Burguillos en la Baja Edad Media extremeña, Badajoz, 1981. Las de Capilla, en Archivo Histórico Nacional, Osuna, leg. 352, núm. 1, leg. 3832, 359 y 360.

(96) Isabel María PÉREZ GonzÁlez: "Ordenanzas de Villalba. Badajoz», en Revista de Estudios Extremeños, XXXV, 2 (1979), 221-277.

(97) Ordenanzas de la muy noble, antigua, grande y leal ciudad de Mérida..., reformadas de las antiguas, Madrid, 1677.

(98) Ordenanzas para el gobierno de la muy noble y muy leal ciudad de Xerez de los Caballeros, aprobadas... en 10 de junio de 1758. Matías Ramón MarTínez Y MARTínez: El Libro de Jerez de los Caballeros, Sevilla, 1892, extracta diversas Ordenanzas de los siglos modernos.

(99) Aurelio PRETEL MARín: Una ciudad castellana en los siglos XIV y XV (Alcaraz, 1300-1475), Albacete, 1978, y La integración de un Municipio medieval en el Estado autoritario de los Reyes Catolicos (la ciudad de Alcaraz, 1475-1525), Albacete, 1979. Luis Rafael Villegas Díaz: Ciudad Real en la Edad Media. La ciudad y sus hombres (1255-1500), Ciudad Real, 1981. Carla R. Phillips: Ciudad Real, 1500-1750. Growth, Crisis and Readjustment in the Spanish Economy, 1979.

(100) Vid. la excelente Colección de Documentos Inéditos para la Historia del Reino de Murcia, editada e inspirada por Juan TORREs FonTEs, Murcia, 1963... Y la edición titulada: Ordenanzas de la muy noble y muy leal ciudad de Murcia. Ordenanzas de huerta y campo, 1695.

(101) Ordenanzas y privilegios de la ciudad de Lorca, Granada, 1713.

(102) Sin ánimo de ser exhaustivo, citaré las obras de Joaquín CERDÁ Rurz-FuNES: «Documentos de Alfonso XI a la ciudad de Murcia (notas sobre la formación de un Derecho local)», en $A H D E$ (1971), y R. SERRA RUIz: «Ordenanzas y reparti- 
En Sevilla hubo Ordenamientos desde el momento mismo de su conquista. Los del siglo XIV se conservan en varias copias (103), y fueron utilizados, en parte, por J. GuIch ot y R. CARANDE (104). En el Xv hubo, sobre todo, Ordenanzas del Municipio, que fueron recopiladas y sistematizadas a comienzos del xVI, imprimiéndose en 1527, y de nuevo en 1632 (105). Por la misma época se compilaban otras muchas en Andalucía: en Córdoba hubo una primera colección en 1435 (106), y otra, mucho más amplia, a comienzos del siglo XVI, todavía inédita, como las de algunas poblaciones de su tierra (107). Por entonces se agruparon los textos de Ordenanza del Municipio de Carmona, muy abundantes en datos, y algo después los de Benacazón, en el Aljarafe sevillano (108); los de Moguer, señorío de los Portocarrero (109); los de las poblaciones del Condado de Niebla y Ducado de Medina Sidonia, en 1504 (110), y los de Jerez de la

miento de Calasparra», en $A H D E$ (1969), además de las Ordenanzas inéditas de Caravaca (Archivo Histórico Nacional, Osuna, leg. 2166, núm. 2, año 1556). También, Juan TORRES FonTes: «El Ordenamiento de precios y salarios de Pedro I al Reino de Murcia», en AHDE (1961), 281-292. María de los Llanos MarTínez CARRILLO: Revolución urbana y autoridad monarquica en Murcia durante la Baja Edad Media (1395-1420), Murcia, 1980. Los diferentes números de la Miscelánea Medieval Murciana (Universidad de Murcia, desde 1974). Rodolfo Bosoue Carceller: Murcia y los Reyes Católicos, Murcia, 1953. Francisco CHacón Jiménez: Murcia en la centuria del quinientos, Murcia, 1979. J. OwENs: Rebelión, monarquía y oligarquía murciana, Murcia, 1980.

(103) José Velázouez Sánchez: Archivo Municipal de Sevilla. Su indice, Sevilla, 1859-1861, 7 vols. Biblioteca Nacional de Madrid, Mss. 692 y 716. Archivo de Simancas, Patronato Real, 58-91. Emilio SÁEZ SÁNCHEZ: "Ordenamiento sobre administración de justicia dado por Pedro I a Sevilla en 1360", en $A H D E$ (1946), 712-750, y «El libro del juramento...», citado en nota 83 , que incluye un Ordenamiento dado a Sevilla en 1412.

(104) Joaquín Guichor Parody: Historia del Excelentísimo Ayuntamiento de... la ciudad de Sevilla, Sevilla, 1896-1904. Ramón CARANDE: Sevilla, fortaleza y mercado, Sevilla, 1972 (2." ed.).

(105) Recopilación de las Ordenanzas de la muy noble e muy leal cibdad de Sevilla, Sevilla, 1527 (reimpresión, 1975). Ordenanzas de la segunda mitad del siglo xv, en Catálogo de la Sección 16.', Archivo Municipal de Sevilla, 1280-1515 (A. Collantes DE TerÁN), Sevilla, 1977, y del mismo autor, Sevilla en la Baja Edad Media. La ciudad y sus hombres, Sevilla, 1977.

(106) Manuel GonZÁlez JiménEZ: «Ordenanzas del Concejo de Córdoba (1435)», en Historia. Instituciones. Documentos, 2 (1975), 189-315.

(107) En el Archivo Municipal de Córdoba. Vid. el artículo de J. M. Bernardo ARES, citado en nota 5. Ordenanzas de Fuenteovejuna, años 1492-1504, en Archivo Histórico Nacional, Osuna, leg. 335, núm. 2.

(108) Ordenanzas del Concejo de Carmona, Sevilla, 1972, ed. de Manuel GoNzÁLEZ JIḾ́NEZ. Las de Benacazón se conservan inéditas en la biblioteca del Instituto de Estudios de Administración Local, en Madrid. Ordenanzas sobre usos agrarios del Aljarafe a comienzos del siglo xvr, en curso de edición por Mercedes BorRero FerNÁNDEZ (Universidad de Sevilla), según ejemplar del Archivo Municipal de Sevilla.

(109) Estudiadas por Antonio GONZALEZ GÓmez: Moguer en la Baja Edad Media (1248-1538), Huelva, 1977.

(110) Archivo de los Duques de Medina Sidonia en Sanlúcar de Barrameda, leg. 687. Otro ejemplar en copia del siglo xviII, sin numerar. Hay también unas Ordenanzas de 1620, dadas por el Duque Manuel Alonso. Estudio y edición de I. GaLÁN PARRA. 
Frontera (111). Otros señoríos que completaron las Ordenanzas de sus poblaciones en el tránsito del siglo Xv al Xvi fueron los de $\mathrm{Pa}$ los desde 1484 a 1523 (112); Alcalá de los Gazules, cuyo señor, Fadrique Enríquez de Ribera, otorgó unas en 1513 (113); Morón, Olvera y Marchena (114), y ya en versión de 1575, Zahara (115), prácticamente al tiempo de Gibraleón, Lepe y Ayamonte (116), o que, en el valle medio del Guadalquivir, Hinojosa y Belalcázar, Cañete de las Torres (117) y Baena, cuyas Ordenanzas han sido editadas en 1907 (118): en ellas se ve la mezcla de preceptos del mismo siglo XvI con otros del $\mathrm{xv}$ aún vigentes. Para el alto valle, se conocen las amplias Ordenanzas de Baeza, compiladas en época de Carlos V (119); las de Quesada, correspondientes a los años 1444 a 1556 (120); las del «común» de la villa de Segura y su tierra, de 1580 (121); las de Canena, y otras varias inéditas (122).

En el Reino de Granada, después de su conquista e incorporación a Castilla, las Ordenanzas aparecen paulatinamente, al tiempo

(111) Archivo Municipal de Jerez de la Frontera. Estudiadas en su tesis doctoral por Antonio GONZÁlEZ GÓMEZ (Universidad de Sevilla).

(112) Antonio GonzÁlez Gómez: «Ordenanzas municipales de Palos de la Frontera (1484-1521)», en Historia. Instituciones. Documentos, 3 (1976), 247-280. Miguel Angel Ladero Quesada: «Palos en vísperas del Descubrimiento», en Revista de Indias, 153-154 (1978), 471-506.

(113) Entique ROMERo DE TORREs, en Boletin de la Academia de la Historia, LVI (1910), págs. 72 y sigs., da noticia de unas Ordenanzas municipales de Alcalá de los Gazules, año 1513, otorgadas por su señor, don Fadrique Enríquez de Ribera.

(114) Archivo Histórico Nacional, Osuna, leg. 82, 93 y 1618.

(115) Archivo Municipal de Zahara, inéditas.

(116) Gibraleón en Archivo Histórico Nacional, Osuna, leg. 382, núms. 59 bis a 74. Antonio GonzÁlez Gómez: Ordenanzas municipales de Lepe, Huelva, 1982.

(117) María de la Concepción Quintanilla Raso: «Ordenanzas municipales de Cañete de las Torres (Córdoba), 1520-1532», en Historia. Instituciones. Documentos, 2 (1975), 483-521. Las de Belalcázar e Hinojosa, en Archivo Histórico Nacional, Osuna, leg. 3829, núm. 1, leg. 329 y 334.

(118) F. Valverde Perales: Antiguas Ordenanzas de la villa de Baena. Siglos XV y XVI, Córdoba, 1907 (reimpresión, 1976).

(119) Carmen ARgente del Castillo Ocaña y José Rodríguez Molina: Reglamentación de la vida de una ciudad en la Edad Media. Las Ordenanzas de Baeza, inédito, \& publicar por el Instituto de Estudios Jiennenses.

(120) Juan de Mata Carriazo y Arroquia: Colección diplomática de Quesada, Jaén, 1975. Incluye las Ordenanzas de los años 1444 a 1556.

(121) Emilio de la Cruz Agullar: Ordenanzas del común de la villa de Segura y su Tierra de 1580. Estudio, texto, glosario, Jaén, 1980.

(122) María Luisa PARdo Rodríguez: «Las Ordenanzas municipales de la villa de Canena (Jaén)», en Homenaje... Hernández Díaz, Universidad de Sevilla... Entre las inéditas, las de Jaén, en su Archivo municipal. 
que se organiza su régimen municipal. Así, sucede que los mismos Reyes dan Ordenamientos para establecerlo en diversas poblaciones, y que regularon el funcionamiento del de Granada capital incluso antes de la conversión al cristianismo de sus habitantes mudéjares (123). Con posterioridad, el Municipio hizo imprimir el conjunto de sus Ordenanzas en 1552, reeditadas en 1672 (124). El de Málaga realizó la misma operación en 1611 (125). En otras poblaciones del Reino, el proceso sería similar, pero sólo se han editado hasta hoy las Ordenanzas de Antequera (126) y algunos textos menores, pero excelentes, para comprender el proceso de elaboración del Derecho municipal del Reino de Granada (127). Por la misma época comenzaba la historia de los Municipios castellanos en las Islas Canarias (128), y con ella la de sus Ordenanzas: han sido editadas las de Tenerife (129), Las Palmas de Gran Canaria (130), El Hierro (131) y Santa Cruz de la Palma (132), estas dos últimas ya del siglo xviII, y las dos primeras de comienzos del xvi en su contenido más importante, cuyo parentesco con los textos andaluces es muy notable.

(123) Miguel Angel LAdERo Quesada: «La repoblación del Reino de Granada anterior al año 1500», en Hispania, 110 (1968), 489-563.

(124) Ordenanzas que los muy ilustres y magníficos señores de Granada mandaron guardar para la buena governación de su república, Granada, 1552 y 1672. Vid. también Francisco de Paula Valladar: Las Ordenanzas de Granada y las actas industriales granadinas, Granada, 1915.

(125) Ordenanzas de la... ciudad de Málaga, Málaga, 1611. Muchas son de comienzos del siglo xvi.

(126) Francisco Alijo Hidalgo: Ordenanzas de Antequera (1531), Málaga, 1979.

(127) José Manuel PÉREZ-PRENDEs: «El Derecho municipal...» (nota 7).

(128) José Peraza de Ayala: Las Ordenanzas de Tenerife y otros estudios para la historia municipal de Canarias, Tenerife, 1976. Leopoldo de la Rosa Olrvera: Evolución del Régimen local en las Islas Canarias, Madrid, 1946, y "Los comienzos de la vida municipal en Tenerife», en Estudios en homenaje a Jordana de Pozas, Madrid, III, 2., pp. 247-260. Pedro Cullén DEL CAstillo: Libro Rojo de Gran Canaria o Gran Libro de Provisiones y Reales Cédulas, Las Palmas de Gran Canaria, 1947. Y la edición de Acuerdos del Cabildo de Tenerife, citada en nota 11.

(129) José Peraza: Las Ordenanzas...

(130) Francisco Morales Padrón: Ordenanzas del Concejo de Gran Canaria, 1531, Las Palmas de Gran Canaria, 1974.

(131) José Peraza de Ayala y Rodrigo de Vallabriga: "Los antiguos Cabildos de las Islas Canarias», en $A H D E$, IV (1927), 225-297. Edita las Ordenanzas de El Hierro de 1705.

(132) Ed. en curso a cargo de Juan RÉgulo PÉREZ (Universidad de La Laguna de Tenerife). 


\section{EL CONTENIDO DE LAS ORDENANZAS}

Tenemos noticia y posibilidad de consultar, en resumen, más de un centenar de referencias, estudios o ediciones sobre Ordenanzas locales, promulgadas por los mismos Municipios en la mayor parte de las ocasiones, en otras por los Reyes o por los señores, a partir de la segunda mitad del siglo XIII, aunque estemos muy lejos de haber alcanzado un nivel relativamente completo o satisfactorio de noticias sobre esta fuente documental, dada la situación $\tan$ desigual en que se halla su inventariado y edición. No obstante, al cotejar los casos conocidos, se comprueba que no es difícil hacer un esquema o elenco general de temas y puntos tocados en las Ordenanzas, aunque no en todas ni de manera semejante. El que se expone a continuación es sólo una guía muy sucinta para encuadrar mejor los contenidos y permitir más adelante estudios comparativos sobre diversas áreas temáticas, utilizando grupos amplios de Ordenanzas, homogéneos en razón de la época en que se promulgaron o por pertenecer a la misma área regional.

A) La organización y funcionamiento del Concejo.-Casi todas las Compilaciones y Ordenanzas se ocupan de ello, a menudo desarrollando lo dispuesto en Ordenamientos y Privilegios Reales, a los que completan. Tales disposiciones suelen figurar en la parte primera de las Ordenanzas, y se refieren a estos puntos, por regla general:

a) La composición del regimiento. Las formas de designación de sus miembros y de los oficiales a su servicio.

b) El funcionamiento del regimiento:

- Las reuniones de Cabildo. Días, horas y lugares. Formas de citación. Cabildos ordinarios y extraordinarios.

- Las deliberaciones: ausencias, turnos de palabra, votaciones y acuerdos. Secreto de lo tratado. Cumplimiento o revocación de acuerdos.

- Escribano del Cabildo. Actas de las reuniones. 
c) La justicia:

- Alcaldes ordinarios. Alcalde de la justicia. Alcaldes mayores. Oficiales menores de justicia.

- Procedimiento de actuación: emplazamientos, lugares y días de juicio, cumplimiento de sentencia.

- Los alguaciles y el orden público. Circulación nocturna. Rufianes y vagabundos. Los carceleros.

- Los escribanos públicos.

d) Los diversos oficiales concejiles y sus misiones peculiares:

- Los jurados. Los personeros.

- Los fieles. El almotacén. Los visitadores.

- El mayordomo. Los contadores.

- Los oficiales menores: pregoneros, guardas de monte, mesegueros, viñaderos.

- El procurador del Concejo.

e) Las intervenciones externas en el régimen municipal: de la Corona. De los señores.

B) Vecindario.-En bastantes ocasiones, las Ordenanzas se refieren también al resto del vecindario, a su consideración como tal y a diversas obligaciones públicas del mismo, en especial las militares:

a) Los vecinos. La adquisición de vecindad. Los albarranes.

b) Padrones de cuantías y forma de efectuarlos.

c) Obligaciones y regímenes militares. Padrones de alardes.

d) Tenencia y provisión de castillos y fortalezas.

C) Los bienes de propios. La fiscalidad concejil:

a) Las distintas rentas y derechos municipales. Generalmente, no se alude a sisas o imposiciones extraordinarias.

b) Las multas, su reparto.

c) Los inmuebles urbanos municipales. Uso o arrendamiento. 
d) Las fincas rústicas en régimen de propios. Su arrendamiento.

e) Los tipos de gasto municipal. Este extremo se contempla con menor frecuencia y sólo en algunos aspectos, como es el salario habitual de los oficiales municipales, pero no en otros, como son la contratación de obras y servicios públicos. Por ejemplo: reparo de murallas, calzadas y puentes, pavimentación, Casa Ayuntamiento, Casa o Audiencia de justicia, cárcel, carnicerías y pescaderías, hospitales, estudio o escuela, limpieza, fiestas, organización de feria o mercado, mensajeros, pleitos...

D) El marco de la vida urbana. Policía urbana:

a) Urbanismo: murallas y fortificaciones, licencia de obras, calles: pavimentación, fachadas, orden en las construcciones. Caminos y puentes. Los alarifes municipales o maestros de obras.

b) La limpieza de plazas, calles, fuentes y otros lugares públicos. Alcantarillado.

c) El emplazamiento de actividades malsanas o sucias: mataderos, tenerías, cría de cerdos, palomares, basureros.

d) Regulación de ciertas actividades y servicios: mesones, baños, mancebías.

E) El abastecimiento y sus condiciones:

a) Las prohibiciones de exportación o «saca».

b) El abasto de productos básicos:

- Agua. Cursos de agua. Fuentes y abrevaderos.

- Pan y harina. Hornos, tahonas, molinos.

- Carne. Carnicerías. Venta de caza.

- Pescado. Pescaderías.

- Vino. Entrada de vino de vecinos y de forasteros.

- Aceite.

- Cal, teja, ladrillo. Madera. 
- Otros productos: sal, miel y cera, queso, azúcar, hortalizas y frutas.

c) Control y fijación de precios, pesas y medidas.

F) Comercio y mercado urbano:

a) Ferias y mercados. Seguridad en el transporte de productos.

b) Venta en tiendas, plazas y otros lugares reservados.

c) La reventa: regatones y regateras.

d) Corredores.

e) Abastecedores oficiales o «mercaderes de mantenimientos».

f) Condiciones de venta, regulación y vigilancia del comercio, en general. Venta en días festivos.

G) Actividad y Ordenanza de los diversos oficios:

a) La organización gremial. Veedores y Alcaldes de oficios.

b) Textil: producción, distribución y venta.

c) Construcción.

d) Cuero.

e) Metal.

f) Barro, tonelería y cestería.

g) Artes: plateros y orfebres. Candeleros y cereros.

h) Medicina. Especiería. Botica.

i) Hostelería.

j) Transporte: carreteros, acemileros. Régimen de navios.

k) Jornaleros y otros trabajadores.

l) Esclavos.

H) La economía agraria:

a) Las tierras de propiedad particular:

- Su régimen administrativo. Su protección contra daños y expolios. 
- Disposiciones sobre heredades, «panes» y sementeras, huertas, viñas y olivares, prados, dehesas y cotos.

- Obligaciones comunales en propiedad privada.

b) La propiedad comunal:

— La defensa jurídica: pleitos y guarda de límites y términos.

- La utilización:

- Eras.

- Zonas de pasto y regulación de su uso. Dehesas boyales. Prados de caballos.

- «Tierras vagas» o «entradizas» y cesiones a terrazgo en baldíos: régimen de usufructo.

- Aprovechamientos forestales.

- Actividades recolectoras: caza, pesca, frutos y raíces, esparto, grana...

- «Asientos» de colmenas.

c) El pastoreo. Las mestas locales. La regulación de la actividad ganadera.

d) Otros aspectos de policía rural: fuegos y rozas. Caminos y veredas. Cursos de agua.

\section{CONCLUSION}

La riqueza de temas que ofrece el contenido de las Ordenanzas locales es tanta que reclama el planteamiento de planes globales de trabajo que permitan tanto su análisis comparativo como la relación con otros tipos de fuentes documentales, más que una yuxtaposición interminable de investigaciones monográficas, aunque, sin duda, éstas continuarán siendo indispensables desde otros puntos de vista. Es preciso también continuar la edición de los textos principales, pero de forma más sistemática, a partir de inventario previo, mejor que al modo seguido hasta ahora, en el que parecen predominar la erudición local, los hallazgos casuales y las publicaciones esporádicas. Merece la pena hacerlo, porque las Ordenan- 
zas ofrecen muchas claves imprescindibles para comprender la vida de la sociedad tradicional en sus marcos locales y cotidianos, precisamente durante los siglos en que aquel sistema social alcanzó su madurez y plenitud organizativa, desde el fin de la crisis bajomedieval hasta la disgregación del Antiguo Régimen económico y político. 